\title{
Pharmacological Profile of Gastric Mucosal Protection by Marmin and Nobiletin from a Traditional Herbal Medicine, Aurantii Fructus Immaturus
}

\author{
Hideki Takase, Kazunori Yamamoto, Hiroyuki Hirano, Yuji Saito and Akira Yamashita \\ Kampo Research Laboratories, Kanebo Ltd., Tomobuchi-cho 1-5-90, Miyakojima-ku, Osaka 534, Japan \\ Received February 23, 1994 Accepted June 20, 1994
}

\begin{abstract}
We studied the effects of marmin and nobiletin on the experimental acute gastric lesions, gastric transmucosal potential difference (PD) and gastric motor activity in rats and the contractions of isolated guinea pig ileum. Oral administration of marmin and nobiletin inhibited both the appearance of ethanol-induced gastric hemorrhagic lesions dose-dependently in a dose range of $10-50 \mathrm{mg} / \mathrm{kg}$, with $\mathrm{ED}_{50}$ values for marmin and nobiletin being 17.2 and $8.0 \mathrm{mg} / \mathrm{kg}$, respectively. However, marmin and nobiletin had minimal effects on aspirin-induced gastric lesions at a dose of $50 \mathrm{mg} / \mathrm{kg}$, respectively. Marmin and nobiletin had no significant influence on the basal PD. Intragastrical administration of marmin and nobiletin at a dose of $25 \mathrm{mg} / \mathrm{kg}$ significantly prevented the PD reduction induced by ethanol. Both marmin and nobiletin given intragastrically at $25 \mathrm{mg} / \mathrm{kg}$ significantly inhibited gastric motor activity measured as intraluminal pressure recordings. Marmin and nobiletin exhibited concentration-dependent relaxations of contractions induced by acetylcholine, transmural electrical stimulation and histamine in isolated guinea pig ileum, respectively. These findings suggest that the anti-ulcer effects of marmin and nobiletin are ascribed primarily to the maintenance of the mucosal barrier integrity and inhibition of gastric motor activity and secondarily due to the prevention of the effects of endogenous acetylcholine and histamine.
\end{abstract}

Keywords: Marmin, Nobiletin, Gastric mucosal protection, Gastric motor activity, Gastric transmucosal potential difference

The hot-water extract of Aurantii fructus immaturus has been used for a long time in traditional medical practice such as for the treatment of stomach disorders, and the anti-inflammatory and anti-allergy actions of the hotwater extract of Aurantii fructus immaturus have been previously reported $(1,2)$.

Recently, we have found that the hot-water extract of Aurantii fructus immaturus inhibited the formation of ethanol- or aspirin-induced gastric lesions (3). Furthermore, we have extracted, fractionated, isolated, purified and determined the chemical composition of the active ingredients from the hot-water extract of Aurantii fructus immaturus (3). The compounds extracted from the hotwater extract of Aurantii fructus immaturus, which inhibited ethanol-induced gastric mucosal damage, were identified as marmin (7-(6,7'-dihydroxygeranyl-oxy)coumarin, Fig.1) and nobiletin $\left(5,6,7,8,3^{\prime}, 4^{\prime}\right.$-hexamethoxyflavone, Fig. 1) (3).

Marmin inhibited the contraction induced by $\mathrm{BaCl}_{2}$ in

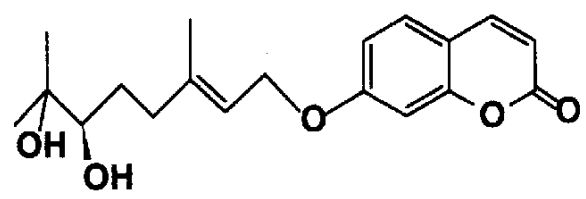

Marmin<smiles>COc1ccc(-c2cc(=O)c3c(OC)c(OC)c(OC)c(OC)c3o2)cc1OC</smiles>

Nobiletin

Fig. 1. Chemical structures of marmin and nobiletin. 
isolated guinea pig ileum and acted as a kind of calcium antagonist on the calcium uptake of myocardial cells (4, 5). Nobiletin inhibited cAMP phosphodiesterase (6), had the inhibitory effect on rat passive cutaneous anaphylaxis (PCA) and had the inhibitory activity on histamine release increased (7). However, the anti-ulcer effects of marmin and nobiletin have not been studied.

To elucidate the anti-ulcer effects and pharmacological profiles of marmin and nobiletin, we examined the effects of marmin and nobiletin on ethanol- or aspirin-induced gastric lesions, basal transmucosal potential difference (PD) or ethanol-induced PD reduction and gastric motor activity in rats in vivo and the ileal contractions induced by acetylcholine, transmural electrical stimulation or histamine in guinea pig in vitro in comparison with the effects of pirenzepine.

\section{MATERIALS AND METHODS}

\section{Procedure for isolation of marmin and nobiletin}

Marmin and nobiletin were isolated from the plant, Aurantii fructus immaturus as described previously (3). Briefly, hot-water extracts of Aurantii fructus immaturus $(2.6 \mathrm{~kg})$ were subjected successively to silica gel column chromatography (developed with a mixture of methylene chloride and methanol) to yield marmin $(0.58 \mathrm{~g})$ and nobiletin $(0.30 \mathrm{~g})$. The structures of marmin and nobiletin were determined by spectroscopic methods (UV, MS, IR, ${ }^{1} \mathrm{HNMR}$ and ${ }^{13} \mathrm{CNMR}$ ) and chemical transformation.

\section{Animals}

Male Wistar rats (ST substrain from Japan SLC, Inc., Hamamatsu), weighing $180-280 \mathrm{~g}$, were used for the in vivo studies. The rats were fasted overnight, but allowed free access to water up to the beginning of the experiment. For the in vitro studies, male guinea pigs (from Japan SLC, Inc.), weighing 250-550 g, were used.

\section{Ethanol-induced gastric lesions}

Ethanol-induced gastric mucosal lesions were produced according to the method of Robert et al. (8). Each drug or vehicle was given to rats orally $30 \mathrm{~min}$ prior to oral administration of $1 \mathrm{ml}$ of $99.5 \%$ ethanol. One hour after ethanol treatment, the animals were killed. The stomach was removed and inflated by injecting $10 \mathrm{ml}$ of $1 \%$ formalin to the gastric lumen for $10 \mathrm{~min}$. Subsequently, the stomach was incised along the greater curvature and examined for lesions. The length $(\mathrm{mm})$ of each lesion was measured under a dissecting microscope $(\times 10)$ with a square grid, and the sum per stomach was used as the lesion index.

\section{Aspirin-induced gastric lesions}

Aspirin-induced gastric mucosal lesions were produced according to the method of Brodie and Chase (9). Each drug or vehicle was given to rats orally $30 \mathrm{~min}$ prior to oral administration of $200 \mathrm{mg} / \mathrm{kg}$ aspirin. Four hours after aspirin treatment, the animals were killed immediately after intravenous injection of $0.5 \mathrm{ml}$ of $5 \%$ Evan's blue. The stomach was removed and inflated by injecting $10 \mathrm{ml}$ of $1 \%$ formalin solution to the gastric lumen for $10 \mathrm{~min}$. Subsequently, the stomach was incised along the greater curvature and examined for lesions. The length ( $\mathrm{mm}$ ) of each lesion was measured under a dissecting microscope $(\times 10)$ with a square grid, and the sum per stomach was used as the lesion index.

\section{Gastric potential difference ( $P D)$}

The experimental procedure was the same as that described by Nagashima et al. (10). After anesthesia with urethane $(1.25 \mathrm{~g} / \mathrm{kg}$, i.p.), the trachea of the rat was cannulated. The abdomen was opened and the stomach exposed. The esophagus was ligated without disturbing the vagus nerve. One catheter filled with $3 \%$ agar in saturated $\mathrm{KCl}$ was inserted into the stomach through an incision in the duodenum and served as the intragastric electrode. A temporary gastric fistula was prepared by inserting a polyethylene tube into the forestomach. The fistula, which led to a three-way tap, was used for intragastric instillation and removal of gastric content. A second catheter filled with $3 \%$ agar and saturated $\mathrm{KCl}$ was inserted into the peritoneal cavity and served as the indifferent electrode. Both the intragastric and intraperitoneal electrodes were placed in separate beakers containing saturated $\mathrm{KCl}$ solution in which a balanced $\mathrm{Ag}-\mathrm{AgCl}$ electrode was positioned. The whole interior of the stomach was gently rinsed with warm saline 3-4 times, and then $4 \mathrm{ml}$ of saline was instilled into the stomach. The changes of PD were continuously monitored by a recorder connected to the millivoltometer. PD recordings were taken at 5 -min intervals during a $30-\mathrm{min}$ period. The gastric PD measurements were done at the forestomach portion where the tip of the detecting electrode was placed. The influence of drugs on gastric PD was estimated by comparison with the values of $P D$ in the corresponding control group after treatment with ethanol or drug alone. Each drug or vehicle was intragastrically administered through the fistula before treatment with $50 \%$ ethanol.

\section{Gastric motor activity}

Gastric motor activity was measured in conscious rats using a balloon positioned in the glandular part of the stomach, following the procedure described by Takeuchi and Nobuhara (11). Briefly, under ether anesthesia, a balloon (containing $0.8 \mathrm{ml}$ of water) and support catheter 
were placed in the glandular stomach through an incision of the forestomach. A temporary gastric cannula for administration of each test drug was placed into the forestomach. The animals were then placed in Bollman cages, and the support catheter was connected to a pressure transducer and polygraph device (Nihon Kohden, Tokyo). Gastric motor activity was continuously monitored on a recorder as intraluminal pressure for a 2-hr test period. Quantitative analysis of gastric motor activity was performed by counting the number of contractions with an amplitude of $10 \mathrm{cmH}_{2} \mathrm{O}$ or greater and by measuring the amplitude of each contraction (clear spike) over a 30-min period. Changes of the motor activity for each animal were expressed as a percentage of the frequency or the amplitude values to the corresponding values observed before administration of each drug. Data were presented as the mean \pm S.E. for each time period from five to ten rats per group. Each drug or vehicle was given intragastrically through the cannula after the motor activity had been well stabilized.

\section{Contractile response of smooth muscle strips of guinea pig ileum}

Male guinea pigs were killed by stunning and exsanguination. The ileum was removed, dissected free of mesentery, and 2-cm segments of the mid-region ileum were set up in organ baths containing Tyrode solution $(137.9 \mathrm{mM}$ $\mathrm{NaCl}, 2.7 \mathrm{mM} \mathrm{KCl}, 0.5 \mathrm{mM} \mathrm{MgCl} \cdot 6 \mathrm{H}_{2} \mathrm{O}, 1.1 \mathrm{mM}$ $\mathrm{NaH}_{2} \mathrm{PO}_{4} \cdot 2 \mathrm{H}_{2} \mathrm{O}, \quad 1.8 \mathrm{mM} \quad \mathrm{CaCl}_{2} \cdot 2 \mathrm{H}_{2} \mathrm{O}, \quad 11.9 \mathrm{mM}$ $\mathrm{NaHCO}_{3}$ and $5.6 \mathrm{mM}$ glucose, in distilled water) gassed with $5 \% \mathrm{CO}_{2}$ and $95 \% \mathrm{O}_{2}$ and maintained at $37^{\circ} \mathrm{C}$. Isometric tension was measured with a mechanical transducer. In the case of transmural electrical stimulated contractions, segments of ileum were set up as described by Paton (12) under $0.5 \mathrm{~g}$ resting tension, and transmural nerve stimulation to the muscle was applied through two parallel platinum rings separated by $10 \mathrm{~mm}$. An electronic stimulator was used to deliver the rectangular pulses of supramaximal voltage and a 2 -msec pulse width of $15 \mathrm{sec}$. When twitch responses to transmural stimulation had become constant, each drug was added to the bathing fluid in a cumulative-concentration schedule. The concentration of each drug required to reduce the twitch response by $50 \%$ was determined. In the case of acetylcholine- or histamine-induced contractions, segments of ileum were mounted on tissue holders under a resting tension of $0.5 \mathrm{~g}$. Contraction with each test drug was obtained by the addition of acetylcholine $\left(10^{-7} \mathrm{~g} / \mathrm{ml}\right)$ or histamine $\left(10^{-7} \mathrm{~g} / \mathrm{ml}\right) 2 \mathrm{~min}$ after application of each test drug. The maximal contractile response obtained with the respective agonist was taken as the $100 \%$ response, and all subsequent contractions were calculated as a percentage of this response.

\section{Drugs}

Marmin, nobiletin and aspirin (Wako, Osaka) were suspended in $5 \%$ gum arabic solution in the in vivo study. Pirenzepine hydrochloride (Sigma, St. Louis, MO, USA), papaverine hydrochloride (Sigma), ethanol (Wako) and urethane (Wako) were dissolved in saline in the in vivo study. Marmin and nobiletin were dissolved in dimethylsulfoxide (DMSO), and pirenzepine hydrochloride, acetylcholine chloride (Sigma) and histamine dihydrochloride (Wako) were dissolved in distilled water in the in vitro study. The final concentration of DMSO in the bathing solution did not exceed $0.1 \%$, and DMSO had no effect on the smooth muscle contraction at the final concentration.

\section{Statistical analyses}

All data are expressed as means \pm S.E. The statistical significances were assessed by Dunnett's multiple comparison test following one-way analysis of variance (ANOVA) or by the $t$-test for paired results. $P$ values less than 0.05 were considered statisitically significant. The $\mathrm{ED}_{50}$ values and $\mathrm{IC}_{50}$ values (with $95 \%$ confidence limits) were calculated by the probit method.

\section{RESULTS}

\section{Ethanol-induced gastric lesions}

Severe band-like mucosal lesions were induced in the glandular stomach by $99.5 \%$ ethanol; the lesion index in the control group was $65.3 \pm 14.3 \mathrm{~mm}(\mathrm{~N}=8)$. Marmin and nobiletin at doses ranging from 10 to $50 \mathrm{mg} / \mathrm{kg}$, p.o. inhibited the formation of gastric lesions induced by

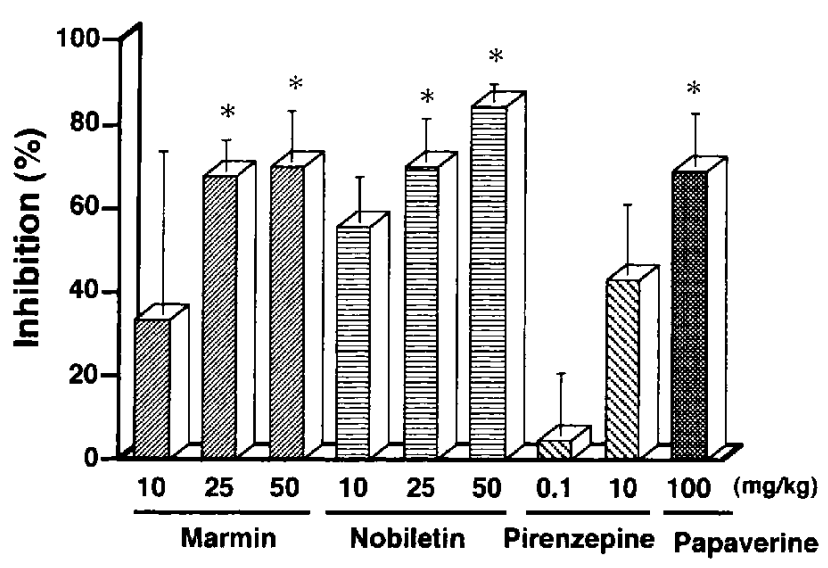

Fig. 2. Inhibitory effects of marmin, nobiletin, pirenzepine and papaverine on ethanol-induced gastric lesions in $24 \mathrm{hr}$-fasted rats. Gastric lesions were produced by ethanol $(99.5 \%, 1 \mathrm{ml} / \mathrm{rat}$, p.o. $)$ in $24 \mathrm{hr}$-fasted rats. Each drug or vehicle was given orally $30 \mathrm{~min}$ before ethanol administration. Animals were killed $1 \mathrm{hr}$ after ethanol treatment. Each value represents the mean \pm S.E. of 5 to 8 rats per group. ${ }^{*} \mathrm{P}<0.05$, significantly different from each control (vehicle-treated group) (Dunnett's $t$-test). 


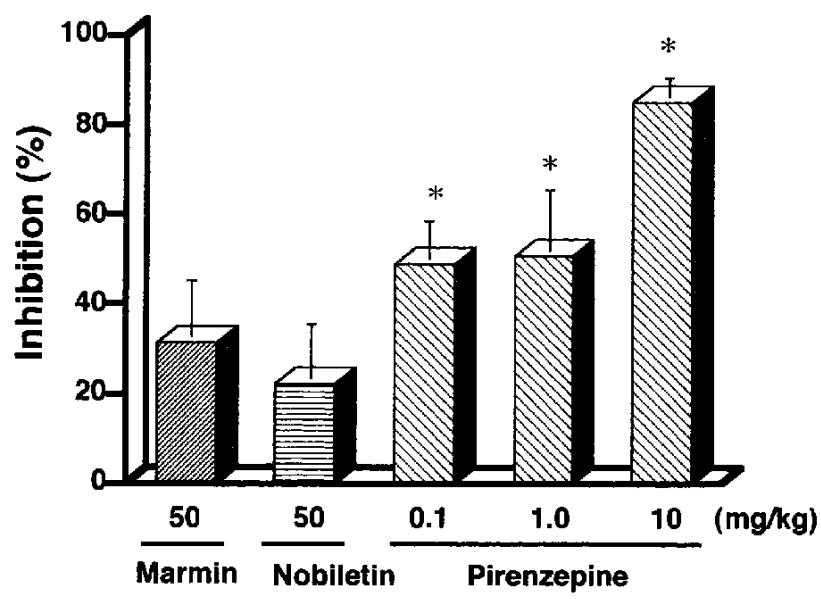

Fig. 3. Inhibitory effects of marmin, nobiletin and pirenzepine on aspirin-induced gastric lesions in rats. Gastric lesions were produced by aspirin ( $200 \mathrm{mg} / \mathrm{kg}$, p.o.) in $24 \mathrm{hr}$-fasted rats. Each drug was given orally $30 \mathrm{~min}$ before aspirin administration. Animals were killed $4 \mathrm{hr}$ after aspirin treatment. Each value represents the mean \pm S.E. of 5 to 8 rats per group. ${ }^{*} \mathrm{P}<0.05$, significantly different from each control (vehicle-treated group) (Dunnett's $t$-test).

ethanol in a dose-dependent manner; the $\mathrm{ED}_{50}$ values for marmin and nobiletin (the doses that produced $50 \%$ inhibition of ethanol-induced gastric lesions) were $17.2(95 \%$ confidence limit: $12.5-21.8)$ and $8.0(3.1-11.8) \mathrm{mg} / \mathrm{kg}$, respectively (Fig. 2). Pirenzepine at the dose of $10 \mathrm{mg} / \mathrm{kg}$ displayed only a $43 \%$ inhibition of the gastric lesions caused by ethanol (Fig. 2). On the other hand, papaverine at $100 \mathrm{mg} / \mathrm{kg}$ showed $69 \%$ inhibition of ethanol-induced gastric lesions (Fig. 2).

\section{Aspirin-induced gastric lesions}

Multiple dotted lesions were produced in the glandular stomach by aspirin $(200 \mathrm{mg} / \mathrm{kg})$; the lesion index in the control group was $23.7 \pm 3.4 \mathrm{~mm}(\mathrm{~N}=8)$. Marmin and nobiletin at $50 \mathrm{mg} / \mathrm{kg}$, p.o. did not significantly inhibit the aspirin-induced gastric lesions, but showed a $32 \%$ and $22 \%$ inhibition, respectively (Fig. 3). On the other hand, pirenzepine $(0.1,1.0$ and $10 \mathrm{mg} / \mathrm{kg})$ dose-dependently prevented the aspirin-induced gastric lesions; the $\mathrm{ED}_{50}$ value and $95 \%$ confidence limit for pirenzepine in the aspirin ulcer model was $0.21(0.06-0.44) \mathrm{mg} / \mathrm{kg}$ (Fig. 3).

\section{The basal PD}

The normal stomach generated a PD of -30 to -35 $\mathrm{mV}$ (basal PD) (Table 1). Intragastrical administration of marmin and nobiletin had no effect on the basal PD. On the contrary, when the stomach was exposed to pirenzepine at $10 \mathrm{mg} / \mathrm{kg}$, the PD was significantly increased.

\section{Ethanol-induced $P D$ reduction}

As shown in Fig. 4, after intragastrical administration of $2 \mathrm{ml}$ of $50 \%$ ethanol, the PD value declined from $-30 \sim-35 \mathrm{mV}$ to $-15 \sim-20 \mathrm{mV}$. Intragastrical administration of marmin and nobiletin at $25 \mathrm{mg} / \mathrm{kg}$ significantly inhibited ethanol-induced $P D$ reduction, but did not significantly inhibit it at $10 \mathrm{mg} / \mathrm{kg}$ (Fig. 4). On the other hand, pirenzepine at $10 \mathrm{mg} / \mathrm{kg}$ did not prevent the PD reduction induced by ethanol (Fig. 4).

\section{Gastric motor activity}

In the normal rat, the stomachs contracted at a frequency of $1-2 / \mathrm{min}$ with an amplitude of $32.3 \pm 6.4 \mathrm{cmH}_{2} \mathrm{O}$ $(\mathrm{N}=10)$ as intraluminal pressure recordings. Intragastrically administered marmin $(25 \mathrm{mg} / \mathrm{kg})$ significantly reduced both the amplitude for $30 \mathrm{~min}$ and the frequency of contractions during $0-60 \mathrm{~min}$ and $90-120 \mathrm{~min}$, and this effect was observed dose-dependently for marmin at 10 and $25 \mathrm{mg} / \mathrm{kg}$ (Figs. 5 and 6 ). In contrast, the intragastrical administration of 10 and $25 \mathrm{mg} / \mathrm{kg}$ of nobiletin significantly reduced the frequency of contractions for 30 $\mathrm{min}$ and for $90 \mathrm{~min}$, respectively, but had no significant effect on the amplitude of contractions (Figs. 5 and 6).

Table 1. Effects of marmin, nobiletin and pirenzepine on basal transmucosal potential difference (PD) in anesthetized rats

\begin{tabular}{|c|c|c|c|c|c|}
\hline \multirow{2}{*}{ Drug } & \multirow{2}{*}{$\begin{array}{c}\text { Dose } \\
(\mathrm{mg} / \mathrm{kg})\end{array}$} & \multirow{2}{*}{$\mathrm{N}$} & \multicolumn{3}{|c|}{ Transmucosal potentail difference $(-\mathrm{mV})$} \\
\hline & & & before drug & after drug & $\Delta \mathrm{PD}$ \\
\hline Control (5\% gum arabic) & - & 4 & $35.0 \pm 1.4$ & $37.3 \pm 2.4$ & $2.3 \pm 0.4$ \\
\hline Marmin & 25 & 4 & $35.3 \pm 2.5$ & $35.5 \pm 3.0$ & $0.2 \pm 0.7$ \\
\hline Nobiletin & 25 & 4 & $36.3 \pm 0.8$ & $39.3 \pm 1.1$ & $3.0 \pm 1.3$ \\
\hline Control (saline) & - & 4 & $36.0 \pm 1.1$ & $36.0 \pm 2.0$ & $0.0 \pm 1.7$ \\
\hline Pirenzepine & 10 & 6 & $34.2 \pm 1.7$ & $39.5 \pm 3.4$ & $5.3 \pm 1.8^{*}$ \\
\hline
\end{tabular}

Each drug was intragastrically instilled for $30 \mathrm{~min}$. Each value represents the mean \pm S.E. of the given number of experiments. ${ }^{*} \mathrm{P}<0.05$, significantly different from each control (paired t-test). 

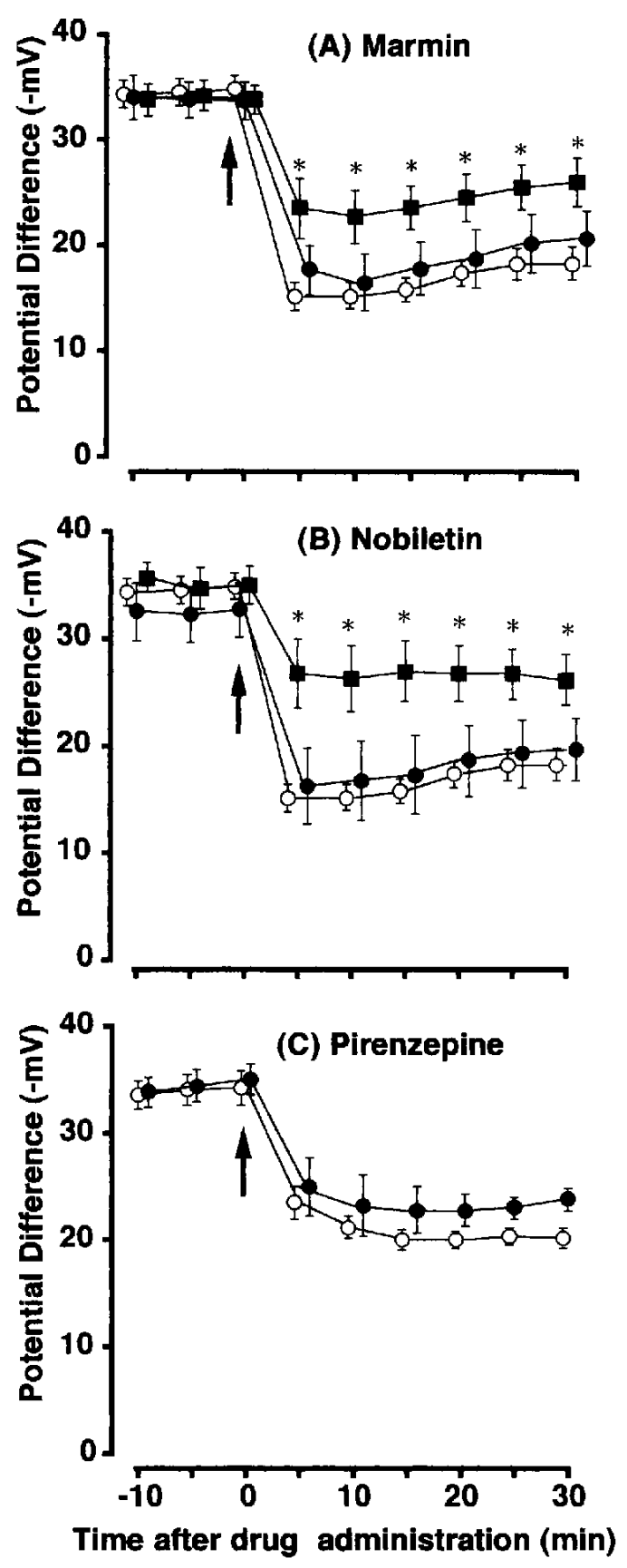

Fig. 4. Effects of marmin, nobiletin and pirenzepine on ethanol-induced transmucosal potential difference (PD) reduction in anesthetized rats. Each drug was intragastrically administered prior to treatment with $50 \%$ ethanol. Each point represents the mean \pm S.E. of 5 to 10 rats per group. $O$ : control (vehicle-treated group); A: marmin, $10(O)$ or $25(\square) \mathrm{mg} / \mathrm{kg}$, i.g.; B: nobiletin, $10(\mathrm{O})$ or 25 (口) $\mathrm{mg} / \mathrm{kg}$, i.g.; C: pirenzepine, $10 \mathrm{mg} / \mathrm{kg}$, i.g. (O). ${ }^{*} \mathrm{P}<0.05$, significantly different from each control (Dunnett's $t$-test).

Pirenzepine $(10 \mathrm{mg} / \mathrm{kg})$ significantly inhibited both the frequency during $0-120 \mathrm{~min}$ and the amplitude for 30 $\mathrm{min}$, and papaverine $(100 \mathrm{mg} / \mathrm{kg})$ significantly suppressed the frequency for $60 \mathrm{~min}$ and the amplitude for $30 \mathrm{~min}$
(Figs. 5 and 6).

Acetylcholine-, transmural electrical stimulation- or histamine-contracted ileum

Figure 7 shows the results for marmin, nobiletin and pirenzepine on the inhibition of acetylcholine (A)-, transmural electrical stimulation (B)- or histamine (C)-contracted ileum. In the acetylcholine-contracted ileum, marmin $\left(10^{-7} \sim 3 \times 10^{-4} \mathrm{~g} / \mathrm{ml}\right)$, nobiletin $\left(10^{-7} \sim 10^{5} \mathrm{~g} / \mathrm{ml}\right)$ and pirenzepine $\left(10^{-8} \sim 10^{-6} \mathrm{~g} / \mathrm{ml}\right)$ produced concentrationdependent relaxation of the contraction, the $\mathrm{IC}_{50}$ values being $2.56 \times 10^{-4}, \quad 3.73 \times 10^{-6}$ and $2.05 \times 10^{-7} \mathrm{~g} / \mathrm{ml}$, respectively. In the transmurally-stimulated ileum, marmin $\left(10^{-7} \sim 3 \times 10^{-4} \mathrm{~g} / \mathrm{ml}\right)$, nobiletin $\left(10^{-7} \sim 10^{-5} \mathrm{~g} / \mathrm{ml}\right)$ and pirenzepine $\left(10^{-8} \sim 10^{-6} \mathrm{~g} / \mathrm{ml}\right)$ produced concentration-dependent inhibition of the twitch response, with the $\mathrm{IC}_{50}$ values of $8.12 \times 10^{-4}, 4.05 \times 10^{-6}$ and $4.52 \times 10^{-8}$ $\mathrm{g} / \mathrm{ml}$, respectively. In the histamine-contracted ileum, marmin $\left(10^{-7} \sim 10^{-4} \mathrm{~g} / \mathrm{ml}\right)$ and nobiletin $\left(10^{-7} \sim 10^{-4}\right.$ $\mathrm{g} / \mathrm{ml}$ ) produced a concentration-dependent relaxation of the contraction, the $\mathrm{IC}_{50}$ values being $3.73 \times 10^{-5}$ and $1.48 \times 10^{-4} \mathrm{~g} / \mathrm{ml}$, respectively, but pirenzepine $\left(10^{-8} \sim\right.$ $10^{-5} \mathrm{~g} / \mathrm{ml}$ ) had little effect on the histamine-induced contractions. Table 2 summarizes the results.

\section{DISCUSSION}

Peptic ulcers are well accepted to be caused by an imbalance between the mucosal defensive factors and the aggressive factors of acid and pepsin (13). The mechanism by which ethanol induces gastric damage is thought to be due to the disruption of the defensive factors such as the gastric mucosal barrier, gastric mucus and mucosal circulation $(14,15)$. On the contrary, gastric acid plays a crucial role in the development of the aspirin-induced gastric lesions (16). The gastric lesion induced by ethanol was markedly prevented by drugs increasing the defensive factors, while the lesion induced by aspirin was prevented by drugs inhibiting the aggressive factors such as gastric acid $(17,18)$. Our previous studies have also shown that sucralfate, 16,16-dimethyl prostaglandin $E_{2}$ and cetraxate, drugs increasing the defensive factors, effectively inhibited ethanol-induced gastric lesions $(17,19)$. Additionally, in the primary experiments, marmin and nobiletin displayed the inhibitory effects in acetylcholine-induced ileal contractions. Therefore, we studied the anti-ulcer effect and the pharmacological profile of marmin and nobiletin in comparison with that of pirenzepine.

In the present study, marmin and nobiletin markedly inhibited the formation of ethanol-induced gastric lesions, and the latter $\left(\mathrm{ED}_{50}\right.$ value $\left.=8.0 \mathrm{mg} / \mathrm{kg}\right)$ was about twice as potent as the former $\left(E D_{50}\right.$ value $\left.=17.2 \mathrm{mg} / \mathrm{kg}\right)$ on the ethanol ulcer inhibition. However, the inhibitory effects 


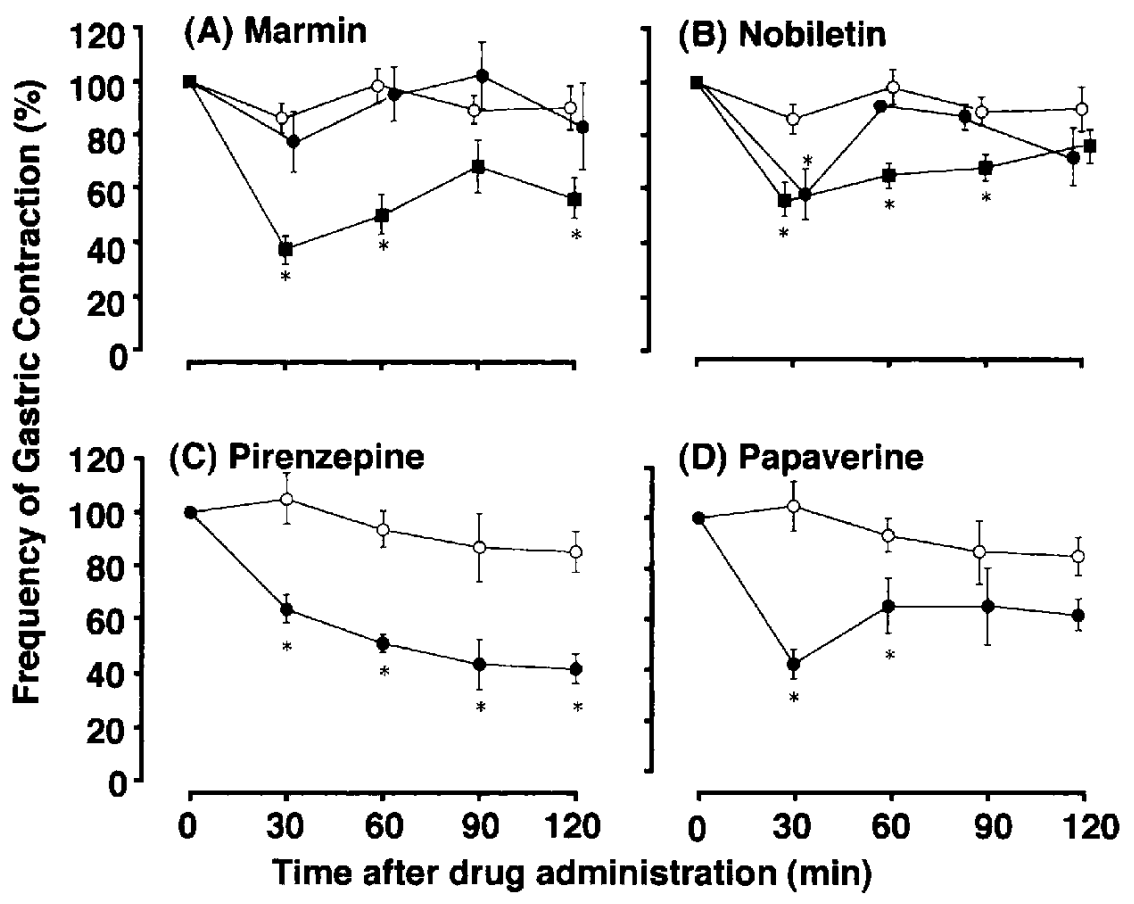

Fig. 5. Effects of marmin, nobiletin, pirenzepine and papaverine on the frequency of gastric contractions in rats measured as intraluminal pressure recordings. Each drug was given intragastrically after basal gastric motor activity had been well stabilized. Data are expressed as the percentage of the frequency values observed before administration of each drug and presented as the mean \pm S.E. of 5 to 10 rats per group. $\bigcirc$ : control (vehicle-treated group); A: $\operatorname{marmin}, 10$ (O) or $25(\mathbf{G}) \mathrm{mg} / \mathrm{kg}, \mathrm{i} . \mathrm{g}$.; B: nobiletin, $10(\bigcirc)$ or $25(\square) \mathrm{mg} / \mathrm{kg}$, i.g.; C: pirenzepine, $10 \mathrm{mg} / \mathrm{kg}$, i.g. (O); D: papaverine, $100 \mathrm{mg} / \mathrm{kg}$, i.g. (O). ${ }^{*} \mathrm{P}<0.05$, significantly different from each control (Dunnett's $t$-test).

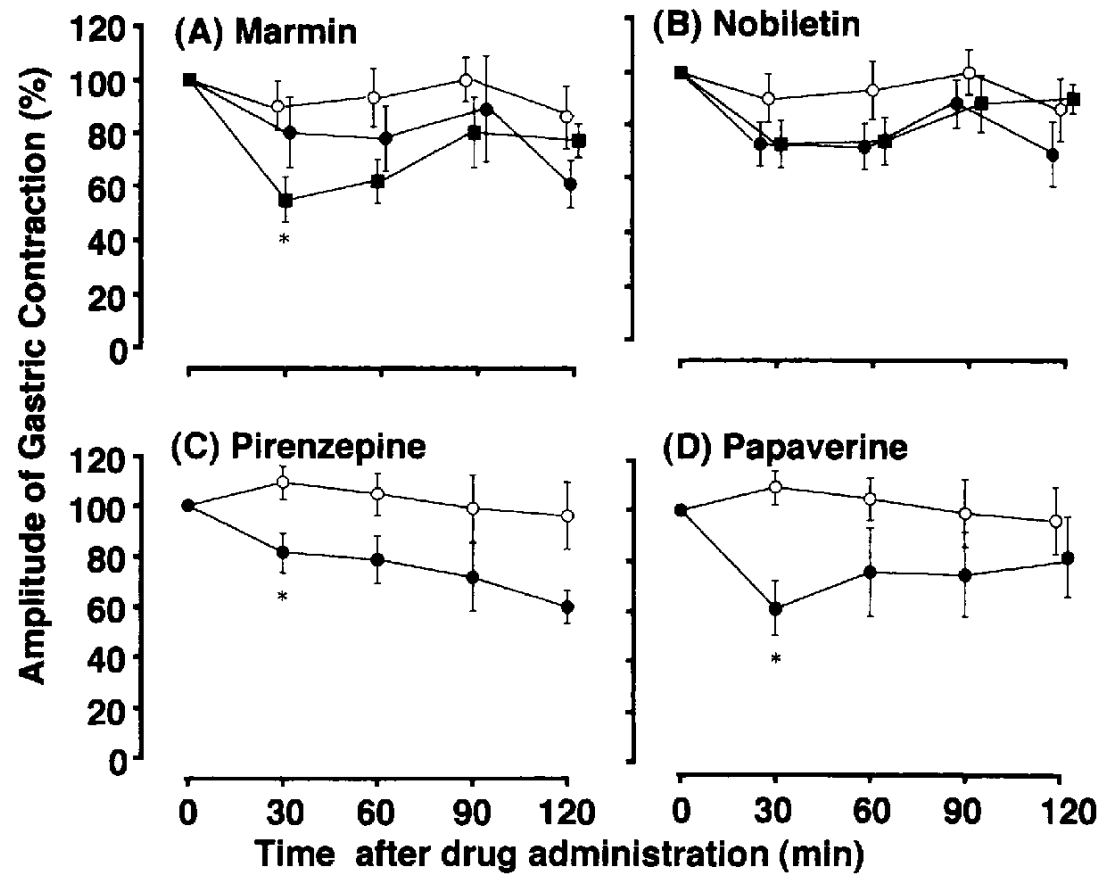

Fig. 6. Effects of marmin, nobiletin, pirenzepine and papaverine on the amplitide of gastric contractions in rats measured as intraluminal pressure recordings. Each drug was given intragastrically after basal gastric motor activity had been well stabilized. Data are expressed as the percentage of the amplitude values observed before administration of each drug and presented as the mean \pm S.E. of 5 to 10 rats per group. $\bigcirc$ : control (vehicle-treated group); A: marmin, $10(\mathrm{O})$ or 25 ( $\mathrm{a}$ ) mg/kg, i.g.; B: nobiletin, $10(\mathrm{O})$ or $25(\mathrm{O}) \mathrm{mg} / \mathrm{kg}$, i.g.; C: pirenzepine, $10 \mathrm{mg} / \mathrm{kg}$, i.g. (O); D: papaverine, $100 \mathrm{mg} / \mathrm{kg}, \mathrm{i} . \mathrm{g} .(\mathrm{O})$. ${ }^{*} \mathrm{P}<0.05$, significantly different from each control (Dunnett's $t$-test). 

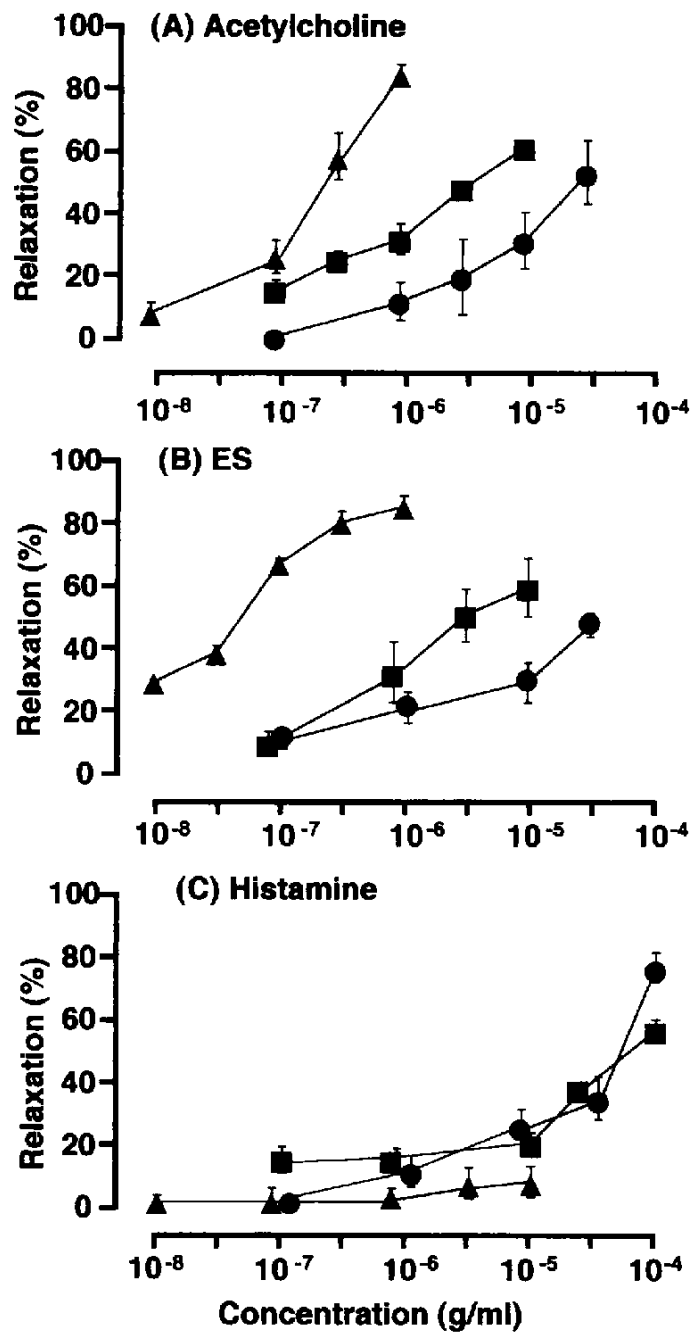

Fig. 7. Relaxatory effects of marmin, nobiletin and pirenzepine against contractions induced by acetylcholine $\left(10^{-7} \mathrm{~g} / \mathrm{ml}\right)(\mathrm{A})$, transmural electrical stimulation (ES: $100 \mathrm{~V}, 2 \mathrm{msec}, 15 \mathrm{sec}$-width) (B) or histamine $\left(10^{-7} \mathrm{~g} / \mathrm{ml}\right)$ (C) in isolated guinea pig ileum. Each value shows the mean \pm S.E. of 4 to 6 experiment.

$\square$ : nobiletin, $\boldsymbol{\Delta}$ : pirenzepine. of these two drugs were smaller in the aspirin ulcer inhibition than in the ethanol ulcer inhibition. On the other hand, pirenzepine, a muscarine $\mathbf{M}_{1}$-receptor antagonist $(20,21)$, strongly prevented aspirin-induced gastric lesions at doses of more than $0.1 \mathrm{mg} / \mathrm{kg}$, doses that inhibit carbachol-induced gastric acid output (data not shown), but showed only a $43 \%$ inhibition of ethanol-induced gastric lesions even at $10 \mathrm{mg} / \mathrm{kg}$, a dose sufficient that inhibit gastric acid secretion. Therefore, it seems that the antiulcer effects of marmin and nobiletin are attributable to another mechanism that suppresses gastric acid secretion.

So-called mild irritants protect the gastric mucosa against strong irritants through the increased synthesis of mucosal prostaglandins (PGs) $(22,23)$. Mild irritants such as dilute ethanol, acetic acid and $\mathrm{NaCl}$ are known to produce a fall in the basal PD as a result of barrier disruption owing to damage in the gastric mucosa $(24,25)$. The cytoprotective properties of marmin and nobiletin seem to be different from those of such mild irritants, since marmin and nobiletin did not cause a fall in the basal PD.

The property of cytoprotection is shared by endogenous PGs, which protect the gastric mucosa against necrotizing agents such as absolute ethanol (8). The gastric $\mathrm{PD}$, which represents the integrity of the gastric mucosal barrier, is considered to well reflect cytoprotective functions, since the PD values decline as a result of barrier disruption owing to damage in the gastric mucosa $(26-30)$. We and other investigators have previously shown that sucralfate and PGs derivatives, increasing the defensive factors, inhibit ethanol-induced PD reduction $(10,31,32)$. In our present study, marmin and nobiletin significantly inhibited the PD reduction induced by ethanol at a dose that ihibited the formation of ethanol-induced lesions, thereby suggesting that marmin and nobiletin at least in part exert cytoprotective activities by maintaining the integrity of the gastric mucosal barrier. On the other hand, pirenzepine did not exhibit such a marked effect against ethanol-induced PD reduction.

The role of gastric motor activity in the pathogenesis of

Table 2. Inhibitory activities of marmin, nobiletin and pirenzepine against contractions induced by acetylcholine, transmural electrical stimulation (ES) or histamine in isolated guinea pig ileum

\begin{tabular}{lccc}
\hline \multirow{2}{*}{ Agonist } & \multicolumn{3}{c}{ IC $_{\text {so }}$ values $(\mathrm{g} / \mathrm{ml})$} \\
\cline { 2 - 4 } & marmin & nobiletin & pirenzepine \\
\hline Acetylcholine & $2.56 \times 10^{-4}$ & $3.73 \times 10^{-6}$ & $2.05 \times 10^{-7}$ \\
& $\left(1.71 \sim 4.45 \times 10^{-5}\right)$ & $\left(2.40 \sim 6.85 \times 10^{-6}\right)$ & $\left(1.59 \sim 2.67 \times 10^{7}\right)$ \\
Electrical stimulation & $8.12 \times 10^{-4}$ & $4.05 \times 10^{-6}$ & $4.52 \times 10^{-8}$ \\
Histamine & $\left(2.91 \sim 54.0 \times 10^{-4}\right)$ & $\left(2.72 \sim 6.72 \times 10^{-6}\right)$ & $\left(3.14 \sim 6.19 \times 10^{-8}\right)$ \\
& $3.73 \times 10^{-5}$ & $1.48 \times 10^{-4}$ & $>10^{-5}$ \\
& $\left(2.59 \sim 5.79 \times 10^{-5}\right)$ & $\left(6.05 \sim 62.7 \times 10^{-5}\right)$ & \\
\hline
\end{tabular}

$\mathrm{IC}_{50}$ values: The concentration that produces the $50 \%$ inhibition. The numbers in parentheses indicate the $95 \%$ confidence limits. 
gastric lesions has been recently suggested $(11,33-35)$. For example, hypermotility might be a major factor in the genesis of gastric lesions induced by a necrotizing agent such as absolute ethanol $(11,33,34)$, because there is a relationship between the grade of ethanol-induced gastric lesions and the increase of gastric motility. In the present study, marmin and nobiletin significantly inhibited gastric motor activity at a dose at which they inhibited ethanol-induced gastric lesions. Similar results were also obtained with papaverine, a non-specific smooth muscle relaxant. These findings suggest that the cytoprotective effects of marmin and nobiletin against gastric mucosal damage is attributed partially to the inhibition of gastric motor activity.

We have previously found that the hot-water extract of Aurantii fructus immaturus significantly inhibited both aspirin-induced and ethanol-induced gastric lesions (3). In this respect, there was a difference between the pharmacological mode of the hot-water extract of Aurantii fructus immaturus and those of marmin or nobiletin. Therefore, further experiments are required to examine which of the other ingredients contained in the hot-water extract of Aurantii fructus immaturus brought about this difference in the pharmacological mode.

Although marmin and nobiletin exhibited the mucosal protective effects, mechanisms of the anti-ulcer action of marmin and nobiletin remain unclear. Acetylcholine released from the cholinergic pathway of vagus nerve endings is considered to participate in modulating the gastric motor activity. Furthermore, there has been evidence showing that a significant amount of histamine is released from the gastric mucosa after damage with ethanol (36) and that mepyramine, a histamine $\mathrm{H}_{1}$-receptor antagonist, significantly suppressed ethanol-induced gastric hypermia (37). Therefore, it is conceivable that endogenous acetylcholine and histamine may play an important role in the development of gastric mucosal damage.

Nobiletin was approximately 15 -fold more potent in preventing the ileal contraction induced by acetylcholine or electrical stimulation than by histamine, but was approximately 18 -fold or 90 -fold less potent in preventing acetylcholine- or electrical stimulation-contracted ileum than pirenzepine. Nobiletin has been reported to show inhibitory effects against cAMP phosphodiesterase and possess an inhibitory effect on histamine release from peritoneal mast cells $(6,7)$. In addition, in the case of smooth muscle, it has been proposed that the inhibition of cAMP phosphodiesterase is closely related to the relaxation of smooth muscle (38). Hence, the relaxatory effect of nobiletin on smooth muscle may be due to the inhibition of cAMP phosphodiesterase. Furthermore, although the inhibitory effect of nobiletin in the ileal contraction in- duced by acetylcholine was weaker than that of pirenzepine, the relaxatory effect of nobiletin on smooth muscle may participate partly in the inhibitory effect of nobiletin against gastric mucosal damage as well as papaverine.

In contrast, marmin inhibited the ileal contraction induced by histamine approximately 7 -fold and 22 -fold more strongly than that induced by acetylcholine and electrical stimulation, respectively, and was approximately 1200 -fold or 60 -fold less potent in preventing acetylcholine-contracted ileum than pirenzepine or nobiletin. However, marmin $\left(\mathrm{IC}_{50}\right.$ value $\left.=3.73 \times 10^{-5} \mathrm{~g} / \mathrm{ml}\right)$ was approximately 1000 times weaker than diphenhydramine $\left(\mathrm{IC}_{50}\right.$ value $\left.=3.16 \times 10^{-8} \mathrm{~g} / \mathrm{ml}\right)$ in preventing histamineinduced ileal contraction. Therefore, the inhibitory effects of marmin on acetylcholine- or histamine-induced ileal contraction could not account for the inhibitory effect of marmin against gastric mucosal damage.

As described above, nobiletin and marmin, unlike pirenzepine, exhibited the protective effects on the mucosal barrier integrity in addition to the inhibition of gastric motor activity associated with the gastric mucosal protection. Additionally, the present findings revealed that nobiletin was more effective in preventing the ileal contraction induced by acetylcholine than by histamine, while marmin showed the reverse.

In summary, the present study revealed that the mucosal protective effects of marmin and nobiletin against ethanol injury were different from those of pirenzepine and mild irritants. Moreover, the present findings suggest that the protective effects of marmin and nobiletin are at least in part ascribed to the maintenance of the mucosal barrier integrity and inhibition of gastric motor activity.

\section{REFERENCES}

1 Koda A, Nishiyori $T$, Nagai $H$, Matsuura $N$ and Tsuchiya $H$ : Anti-allergic action of crude drugs and blended Chinese traditional medicines. Folia Pharmacol Jpn 80, 31-41 (1982) (Abstr in English)

2 Kubo M, Yano M and Matsuda H: Pharmacological study on Citrus fruit. I. Anti-allergic effect of Citrus unshiu markovich (1). Yakugaku Zasshi 109, 835-842 (1989) (Abstr in English)

3 Hirano H, Takase H, Yamamoto K, Abe K and Saito Y: Antiulcer effects of Aurantii fructus immaturus and its anti-ulcer compound. The 114th Annual Meeting of Pharmaceutical Society of Japan, Tokyo, Abstract Supp II, 246P (1994) (in Japanese)

4 Yamada $\mathrm{Y}$, Nakatani N and Fuwa H: Epoxyaurapten and marmin from juice oil Hassaku (Citrus hassaku) and the spasmolytic activity of 7-geranylocoumarin-related compounds. Agric Biol Chem 51, 1105-1110 (1987)

5 Kakiuchi N, Senaratne LRE, Huang SL, Yang XW, Hattori M, Pilapitiya $\mathrm{U}$ and Namba T: Effects of constituents of beli (Aegle marmelos) on spontaneous beating and calcium-paradox of myocardial cells. Planta Med 57, 43-46 (1991)

6 Nikaido T, Ohmoto T, Sankawa U, Hamanaka T and Totsuka 
K: Inhibition of cyclic AMP phosphodiesterase by flavonoids. Planta Med 46, 162-166 (1982)

7 Chun $Y$ and Sankawa U: Screening of antiallergic effect in traditional medicinal drugs and active constituents of Aurantii fructus immaturus. Shoyakugaku Zasshi 43, 314-323 (1989)

8 Robert A, Nezamis JE, Lancaster $\mathrm{C}$ and Hancher AJ: Cytoprotection by prostaglandins in rats: Prevention of gastric necrosis produced by alcohol, $\mathrm{HCl}, \mathrm{NaOH}$, and thermal injury. Gastroenterology 77, 433-443 (1979)

9 Brodie DA and Chase BJ: Role of gastric acid in aspirininduced gastric irritation in the rat. Gastroenterology 53, 604-610 (1967)

10 Nagashima R, Hoshino H, Hinohara $Y$, Sakai K, Hata S and Nakano $H$ : Effects of sucralfate in ethanol-induced gastric mucosal damage in the rat. Scand J Gastroenterol 18, Supp 83, $17-20(1983)$

11 Takeuchi $\mathrm{K}$ and Nobuhara $\mathrm{Y}$ : Inhibition of gastric motor activity by 16,16 -dimethyl prostaglandin $\mathrm{E}_{2}$ : a possible explanation of cytoprotection. Dig Dis Sci 30, 1181-1188 (1985)

12 Paton WDM: The action of morphine and related substances on contraction and acetylcholine output of coaxially stimulated guinea-pig ileum. Br J Pharmacol 12, 119-127 (1957)

13 Shay $\mathrm{H}$ and Sun DCH: Etiology and pathology of gastric and duodenal ulcer. In Gastroenterology 1, 2nd ed, Edited by Bockus HL, p 420, WB Saunders, Comp, Philadelphia and London (1963)

14 Trier JS, Szabo S and Allan CH: Ethanol-induced damage to mucosal capillaries of rat stomach. Ultrastructural features and effects of prostaglandin $F_{2}$ and cysteamine. Gastroenterology 92, 13-22 (1987)

15 Miller TA: Protective effects of prostaglandins against gastric mucosal damage: Current knowledge and proposed mechanism. Am J Physiol 245, G601-G623 (1983)

16 Okabe S, Takeuchi K, Nakamura K and Takagi K: Pathology of gastric lesions induced by aspirin in the pylorus-ligated rat. Jpn J Pharmacol 24, 363-371 (1974)

17 Takase $\mathrm{H}$, Imanishi $\mathrm{K}$, Miura $\mathrm{O}$, Yumioka $\mathrm{E}$ and Watanabe $\mathrm{H}$ : Pharmacological studies on the effects of some traditional Chinese medicines on gastric function. (3) The effects of Orengedoku-to (OGT), San'o-syasin-to (SST), Antyu-san (AS) and Dai-saiko-to (DST) on ethanol- and aspirin-induced gastric lesions in rats. Folia Pharmacol Jpn 91, 319-324 (1988) (Abstr in English)

18 Inatomi $N$, Nagaya $H$, Takami $K$, Shino $A$ and Satoh $H$ : Effects of a proton pump inhibitor, AG-1749 (lansoprazole), on reflux esophagitis and experimental ulcers in rats. Jpn J Pharmacol 55, 437-451 (1991)

19 Takase $\mathbf{H}$, Imanishi K, Miura O, Yumioka $\mathbf{E}$ and Watanabe $\mathbf{H}$ : Features of the anti-ulcer effects of Oren-gedoku-to (a traditional Chinese medicine) and its component herb drugs. Jpn J Pharmacol 49, $301-308$ (1989)

20 Hammer R, Berrier CP, Birdsall NJM, Burgen ASV and Hulme EC: Pirenzepine distinguishes between different subclasses of muscarinic receptors. Nature 283, 90-91 (1980)

21 Hummer $\mathbf{R}$ and Giachetti A: Muscarinic receptor subtypes; $\mathbf{M}_{1}$ and $\mathbf{M}_{2}$ biochemical and functional characterization. Life Sci 31, $2991-2998$ (1982)

22 Konturek SJ, Brozozowski T, Piastucki I, Radecki T,
Dembinski A and Dembinska-Kiec A: A role of locally generated prostaglandins in adaptive gastric cytoprotection. Dig Dis Sci 27, 967-971 (1982)

23 Robert A, Nezamis JE, Lancaster C, Davis JP, Field SO and Hancher AJ: Mild irritants prevent gastric necrosis through "adaptive cytoprotection" mediated by prostaglandins. Am J Physiol 245, G113-G121 (1983)

24 Takeuchi K, Yamakuni H, Nobuhara Y and Okabe S: Functional and morphological alterations in the rat stomach following exposure to hypertonic $\mathrm{NaCl}$ solution. Jpn J Pharmacol 42, $549-560$ (1986)

25 Nobuhara $\mathbf{Y}$, Takeuchi $\mathbf{K}$ and Okabe S: Vinegar is a dietary mild irritant to the rat gastric mucosa. Jpn J Pharmacol 41, $101-108$ (1986)

26 Davenport HW, Warner HA and Code CF: Functional significance of gastric mucosal barrier to sodium. Gastroenterology 47, $142-152$ (1964)

27 Geall MG, Phillips SF and Summerskill WHJ: Profile of gastric potential difference in man: effects of aspirin, alcohol, bile and endogenous acid. Gastroenterology 58, 437-443 (1970)

28 Ivey KL: Gastric mucosal barrier. Gastroenterology 61, 247-257 (1971)

29 Baskin WN, Ivey KL, Krausse WJ, Jefferey GE and Gemmell RT: Aspirin-induced ultrastructural changes in human gastric mucosa correlation with potential difference. Ann Intern Med 85, 299-303 (1976)

30 Pendleton RG and Stavorski JM: Effects of indomethacin, aspirin, and related compounds on the transgastric potential difference in cats. Arch Int Pharmacodyn Ther 263, 146-154 (1983)

31 Takase $\mathrm{H}$, Miura $\mathrm{O}$ and Ito $\mathrm{K}$ : Pharmacological studies of some blended traditional Chinese medicines on gastric function. (1) The effects of Oren-gedoku-to (OGT), San'o-syasin-to (SST), Antyu-san (AS) and Dai-saiko-to (DST) on ethanol- and aspirin-induced injury of gastric mucosal barrier. Folia Pharmacol Jpn 89, 299-306 (1987) (Abstr in English)

32 Chiu PSJ, Gerhart AB, Policelli $M$ and Kaminsky J: Gastric cytoprotective properties of SCH32651, a novel antiulcer agent. Arch Int Pharmacodyn Ther 270, 128-140 (1984)

33 Mersereau WA and Hinchey EJ: Role of gastric mucosal folds in formation of focal ulcers in the rat. Surgery 91, 150-155 (1982)

34 Takeuchi K, Ueki S and Okabe S: Importance of gastric motility in the pathogenesis of indomethacin-induced gastric lesions in rats. Dig Dis Sci 31, 1114-1122 (1986)

35 Yano S, Akahane $\mathrm{M}$ and Harada $\mathrm{M}$ : Role of gastric motility in development of stress-induced gastric lesions of rats. Jpn J Pharmacol 28, 607-615 (1978)

36 Cho $\mathrm{CH}$, Ogle CW, Wang SH and Koo MWL: Effects of zinc sulfate on ethanol- and indomethacin-induced ulcerations and changes in prostaglandin $E_{2}$ and histamine levels in the rat gastric glandular mucosa. Digestion 32, 288-295 (1985)

37 Oater PJ and Hakkinen JP: Studies of the mechanism of ethanol-induced gastric damage in rats. Gastroenterology 94 , $10-21$ (1988)

38 Tanaka $\mathrm{T}$, Ishikawa $\mathrm{T}$, Hagiwara $\mathrm{M}$, Onoda $\mathrm{K}$, Itoh $\mathrm{H}$ and Hidaka H: Effects of cilostazol, a selective cAMP phosphodiesterase inhibitor on the contraction of vascular smooth muscle. Pharmacology 36, 313-320 (1988) 